\title{
Atmospheric inertia-gravity waves retrieved from level-2 data of the satellite microwave limb sounder Aura/MLS
}

\author{
Klemens Hocke $^{1,2}$, Martin Lainer ${ }^{1,2}$, Lorena Moreira ${ }^{1,2}$, Jonas Hagen ${ }^{1,2}$, Susana Fernandez Vidal ${ }^{1,2}$, and \\ Franziska Schranz ${ }^{1,2}$ \\ ${ }^{1}$ Institute of Applied Physics, University of Bern, Bern, Switzerland \\ ${ }^{2}$ Oeschger Centre for Climate Change Research, University of Bern, Bern, Switzerland \\ Correspondence to: Klemens Hocke (klemens.hocke@iap.unibe.ch)
}

Received: 8 June 2016 - Revised: 24 August 2016 - Accepted: 5 September 2016 - Published: 19 September 2016

\begin{abstract}
The temperature profiles of the satellite experiment Aura/MLS are horizontally spaced by $1.5^{\circ}$ or $165 \mathrm{~km}$ along the satellite orbit. These level-2 data contain valuable information about horizontal fluctuations in temperature, which are mainly induced by inertia-gravity waves. Wave periods of $2-12 \mathrm{~h}$, horizontal wavelengths of $200-1500 \mathrm{~km}$, and vertical wavelengths of 6-30 km efficiently contribute to the standard deviation of the horizontal temperature fluctuations. The study retrieves and discusses the global distributions of inertia-gravity waves in the stratosphere and mesosphere during July 2015 and January 2016. We find many patterns that were previously present in data of TIMED/SABER, Aura/HIRDLS, and ECMWF analysis. However, it seems that Aura/MLS achieves a higher vertical resolution in the gravity wave maps since the maps are derived from the analysis of horizontal fluctuations along the orbit of the sounding volume. The zonal mean of the inertia-gravity wave distribution shows vertical modulations with scales of $10-20 \mathrm{~km}$. Enhanced wave amplitudes occur in regions of increased zonal wind or in the vicinity of strong wind gradients. Further, we find a banana-like shape of enhanced inertia-gravity waves above the Andes in the winter mesosphere. We find areas of enhanced inertia-gravity wave activity above tropical deep convection zones at $100 \mathrm{hPa}(z \sim 13 \mathrm{~km})$. Finally, we study the temporal evolution of inertia-gravity wave activity at $100 \mathrm{hPa}$ in the African longitude sector from December 2015 to February 2016.
\end{abstract}

Keywords. Meteorology and atmospheric dynamics (middle atmosphere dynamics; waves and tides)

\section{Introduction}

Atmospheric gravity waves transfer momentum through the atmosphere, and the breaking of gravity waves changes the circulation of the atmosphere (Alexander et al., 2010). According to Fritts and Alexander (2003), gravity waves can be divided into three classes: inertia-gravity waves (or lowfrequency gravity waves), medium-frequency gravity waves, and high-frequency gravity waves. In the case of inertiagravity waves, the Coriolis force has to be considered as a restoring force in addition to the buoyancy force.

High-frequency gravity waves have wave periods less than $1 \mathrm{~h}$, horizontal wavelengths less than $150 \mathrm{~km}$, and vertical wavelengths greater than $10 \mathrm{~km}$. High-frequency gravity waves are most important for transfer of momentum from the lower to the middle and upper atmosphere (Fritts et al., 2016). High-frequency gravity waves can be generated by orography, jet streams and convective activity. Mediumfrequency gravity waves have periods of $1-3 \mathrm{~h}$ and horizontal wavelengths between 150 and $300 \mathrm{~km}$. Numerical simulations by Vadas et al. (2015) showed that ocean surface waves can generate medium- and high-frequency atmospheric gravity waves propagating up to the thermosphere.

Inertia-gravity waves have periods from several hours to $24 \mathrm{~h}$ and horizontal wavelengths from several hundreds of kilometres to about $2000 \mathrm{~km}$. The vertical wavelengths generally decrease with increase of the wave period. A strong inertia-gravity wave was found in the stratosphere above the southern Andes with a vertical wavelength of 6-7 km and a horizontal wavelength of about $400 \mathrm{~km}$ (Eckermann and Preusse, 1999). The Andes wave regularly occurs in high-resolution meteorological analyses during austral winter (Shutts and Vosper, 2011). Hendricks et al. (2014) investi- 
gated the cause of the stratospheric gravity wave belt that extends eastward from the southern Andes to southeast of Australia. They found that this belt of enhanced gravity wave activity is a robust climatological feature due to non-orographic tropospheric gravity wave sources: spontaneous emission from jets in rapidly evolving baroclinic systems, frontogenesis, and convection. Sato and Yoshiki (2008) investigated inertia-gravity wave generation around the polar vortex in the stratosphere above the Syowa station $\left(69^{\circ} \mathrm{S}, 39^{\circ} \mathrm{E}\right)$. They explained that the observed inertia-gravity waves are generated by a spontaneous adjustment around the geostrophically unbalanced polar night jet. The spontaneous generation of inertia-gravity waves above the regions of strong curvature of the tropospheric mid-latitude jet stream was simulated in the study of O'Sullivan and Dunkerton (1995). Williams et al. (2003) studied inertia-gravity waves in the large-scale flow of a rotating, two-layer annulus experiment. Plougonven and Zhang (2014) provided a review about inertia-gravity waves from atmospheric jets and fronts. Kumar et al. (2011) observed inertia-gravity waves generated from tropical cyclones, while Ki and Chun (2011) investigated inertia-gravity waves associated with tropospheric deep convection in Korea. Tsuda et al. (2000) derived a global morphology of gravity wave activity in the stratosphere by using the GPS occultation data of the GPS/MET experiment.

Analysing a meteor train, Suzuki et al. (2013) detected an inertia-gravity wave with a vertical wavelength of $16 \mathrm{~km}$ and an amplitude of $30 \mathrm{~m} \mathrm{~s}^{-1}$ in the mesopause region. Lidar and radar measurements over Antarctica gave evidence for inertia-gravity waves in the polar mesopause region with vertical wavelengths of about $22 \mathrm{~km}$, apparent periods of 5$8 \mathrm{~h}$, horizontal wavelengths of about $1100-2200 \mathrm{~km}$, and horizontal phase speeds of $68-80 \mathrm{~m} \mathrm{~s}^{-1}$ (Chen et al., 2013). Sato and Yoshiki (2008) explained that the large horizontal wind fluctuations of inertia-gravity waves can play a role in wave mixing of atmospheric trace gases. Grygalashvyly et al. (2011) performed atmospheric simulations with and without inertia-gravity waves. Their results strongly suggest that gravity wave mixing of minor constituents represents a very important mechanism for the coupling between the dynamics and the photochemical system of the mesosphere and lower thermosphere.

In the past, the Microwave Limb Sounder on the satellite Aura (Aura/MLS) provided deep insight into the global distributions of high-frequency gravity waves (Jiang et al., 2004a, b, 2005). The retrieved high-frequency gravity waves have horizontal wavelengths less than $140 \mathrm{~km}$ and vertical wavelengths of about $10 \mathrm{~km}$. The high horizontal resolution is reached by using the level-1 data of Aura/MLS, namely the brightness temperature of 20 microwave channels. Wu and Eckermann (2008) presented advanced global and regional distributions of high-frequency gravity wave activity. In addition, they evaluated the high-resolution data of ECMWF meteorological reanalysis. In the conclusions, they suggested a further study to retrieve inertia-gravity waves from the level-2 data of Aura/MLS. Here, we follow this way and we present global distributions of inertia-gravity wave activity in the stratosphere and mesosphere. Observations of global maps of mesospheric inertia-gravity waves are quite novel. We are only aware of a study by Ern et al. (2011) in which they presented global maps of gravity wave momentum flux at $70 \mathrm{~km}$ altitude retrieved from TIMED/SABER observations.

\section{Data analysis}

We apply a data analysis which evaluates the horizontal temperature fluctuations at a fixed pressure level and along the orbit of the sounding volume of the Aura satellite. The advantage of evaluating the horizontal fluctuations is that background features such as the stratopause or the mesopause are not misinterpreted as atmospheric waves. Further, large-scale equatorial waves, tides, or planetary waves with horizontal wavelengths of several thousand kilometres will not be mistaken for inertia-gravity waves. In addition the vertical resolution of the gravity wave maps is of the order of $3-6 \mathrm{~km}$. Such a resolution cannot be achieved by high-pass-filtering the vertical oscillations of temperature profiles.

Recently, Ern et al. (2011) removed the global-scale background temperature distribution by a 2-D-Fourier decomposition in longitude and time. This method is also capable of removing global-scale waves with periods as short as about 12 days, and thus global distributions of gravity-wave momentum flux absolute values can be derived not only in the stratosphere but also in the mesosphere. This demanding data analysis method of Ern et al. (2011) is beyond our capabilities, and we prefer to derive the gravity wave-induced horizontal temperature fluctuations with a simple method which takes advantage of the dense horizontal sampling of Aura/MLS.

The level-2 data consist of atmospheric vertical profiles with a spacing of $165 \mathrm{~km}\left(1.5^{\circ}\right.$ along the satellite orbit which is sun-synchronous with an inclination of $98^{\circ}$ and a period of $98.8 \mathrm{~min}$; Waters et al., 2006; Schwartz et al., 2008). In the present study, we evaluate the mean and the standard deviation of five consecutive temperature values separately at each pressure level from about 100 to $0.001 \mathrm{hPa}$. Before calculation of the standard deviation the data are detrended in order to remove the effect of large-scale, horizontal background variations. We selected five consecutive measurement points, since over a distance of $5 \times 165 \mathrm{~km}$ a straight line fit of the horizontal background variation is a good approximation. The five points are collected within a time interval of $2 \mathrm{~min}$. In the case of more measurement points (e.g. seven) the straight line fit approximation becomes more invalid since the background atmosphere non-linearly varies over long distances. Further, the horizontal resolution of the gravity wave maps would be reduced. On the other hand, in the case of three consecutive points the standard deviation and the mean 


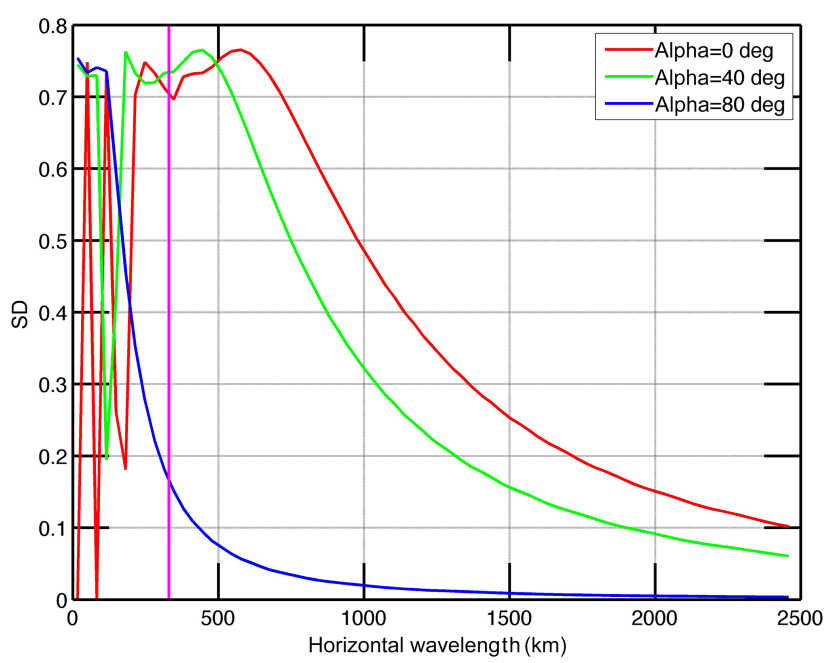

Figure 1. The standard deviation that is calculated by the fiveconsecutive-points method as a function of the horizontal wavelength $\lambda_{\mathrm{h}}$ for artificial sine waves with an amplitude of 1 . The parameter $\alpha$ is the angle between the horizontal wave vector and the orbit of the sounding volume $\left(0^{\circ}\right.$ is wave propagation along the orbit; red line). The apparent wavelength is given by $\lambda_{\mathrm{h}} / \cos \alpha$. The magenta line denotes the Nyquist length when the wavelength is 2 times the sampling length of the near-polar orbit, which is about $165 \mathrm{~km}$. Generally, our method is sensitive to inertia-gravity waves with wavelengths between about 200 and $1500 \mathrm{~km}$. Planetary waves in zonal direction have a high value of $\alpha$ and are nicely suppressed by our method.

are not well defined, and the measurement noise may dominate. Thus, the choice of five consecutive points is the best compromise.

By means of artificial sine waves which are sampled with a spacing of $165 \mathrm{~km}$ along the sounding volume orbit, we can estimate the response of our method. Figure 1 shows the result for different angles $\alpha$ between the horizontal wave vector and the orbit. Waves propagating along the track $\left(\alpha=0^{\circ}\right.$, red line) can have wavelengths of about $1500 \mathrm{~km}$, and they still contribute to the standard deviation. Tides and planetary waves which have a $\alpha$ value of about $80^{\circ}$ (in the case of the near polar orbit of Aura) and large horizontal wavelengths are strongly suppressed by our method as the blue line in Fig. 1 shows. There are aliasing effects left of the magenta line in Fig. 1. Thus, our method includes some noise from high-frequency and medium-frequency gravity waves. Fortunately, the amplitudes of these waves in nature are smaller than the amplitudes of inertia-gravity waves so that the noise and aliasing problem should be not a serious problem for our data analysis. In summary, the standard deviation will be a good proxy for the inertia-gravity waves with horizontal wavelengths from 200 to $1500 \mathrm{~km}$.

Jiang et al. (2004a) explained in detail that the variable angle $\alpha$ between the line of sight and the wave fronts can lead to measurement geometry biases. Preusse et al. (2002)

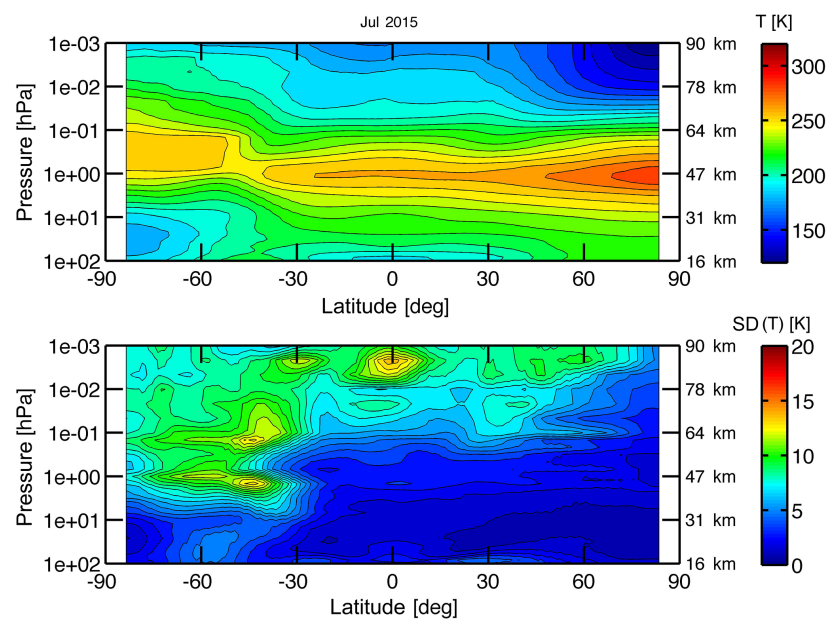

Figure 2. Monthly zonal mean of temperature (upper panel) and its standard deviation ( $\operatorname{SD}(T)$, lower panel) for July 2015 as observed by the satellite experiment Aura/MLS. The cold summer mesopause in the Northern Hemisphere and the cold polar vortex in the lower stratosphere of the southern winter Northern Hemisphere are present.

investigated the sensitivity of space-based measurements of stratospheric mountain waves to the viewing geometry. For the purpose and conclusions of the present study these biases are not so relevant since we are mainly interested in the order of magnitude and the rough geographic distribution of inertia-gravity wave activity.

The vertical resolution of the temperature profiles of Aura/MLS ranges from $3 \mathrm{~km}$ in the stratosphere to $6 \mathrm{~km}$ in the mesosphere (Schwartz et al., 2008). The present study utilizes Aura/MLS data of version 4.2. Temperature fluctuations with vertical wavelengths of 6 to $30 \mathrm{~km}$ are expected to have the strongest response. The approximated dispersion relation of inertia-gravity waves under inclusion of the Coriolis frequency $f$ is (Fritts and Alexander, 2003)

$\hat{\omega}^{2}=N^{2} \frac{k_{\mathrm{h}}^{2}}{m^{2}}+f^{2}$,

where $N$ is the buoyancy frequency, $\hat{\omega}$ is the intrinsic wave frequency, $k_{\mathrm{h}}$ is the horizontal wave number, and $m$ is the vertical wave number. For a constant buoyancy frequency $N=2 \pi / 5 \mathrm{~min}$ and $f$ for $45^{\circ}$ latitude, the intrinsic gravity wave periods are of the order of $2-12 \mathrm{~h}$ for horizontal wavelengths of $200-1500 \mathrm{~km}$ and vertical wavelengths of 6 $30 \mathrm{~km}$, which most efficiently contribute to the standard deviation of the horizontal temperature fluctuations.

Figure 2 shows the zonal mean temperature field and its standard deviations for July 2015. This figure gives a first orientation. In the present study we intercompare the data of July 2015 and January 2016. As expected, the mesopause temperature has a minimum in the summer Northern Hemisphere in Fig. 2. The standard deviation of the zonal averages is around $10 \mathrm{~K}$ in the winter stratosphere while the sum- 

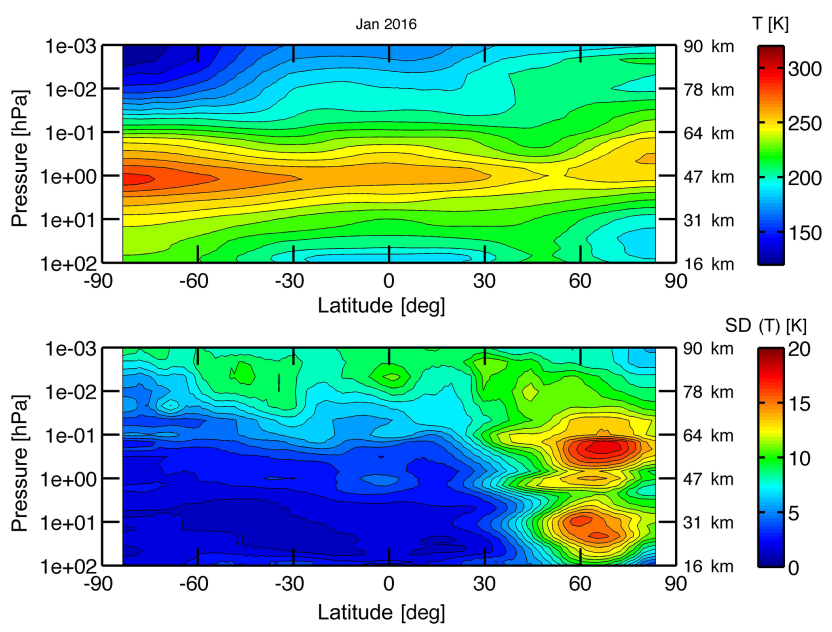

Figure 3. Monthly zonal mean of temperature (upper panel) and its standard deviation ( $\mathrm{SD}(T)$, lower panel) for January 2016 as observed by the satellite experiment Aura/MLS. Compared to the winter Southern Hemisphere in Fig. 2, the winter Northern Hemisphere shows larger stratospheric temperature variations, which are mainly due to planetary Rossby waves and the deformation and displacement of the stratospheric polar vortex.

mer stratosphere is very quite $(<5 \mathrm{~K})$. Figure 3 shows the zonal mean temperature field and its standard deviations for January 2016. In the winter Northern Hemisphere the standard deviation of the zonal means reaches high values of $20 \mathrm{~K}$. Indeed, the winter 2015/2016 showed large deformations and displacements of the stratospheric polar vortex with zonal wave numbers 1 and 2. Generally, the mesopause region of Fig. 3 shows higher values of the standard deviation compared to Fig. 2. In summary, the temperature profiles of Aura/MLS seem to have a high quality and they might be usable over the range from 15 to $100 \mathrm{~km}$ altitude, though the recommendation of Schwartz et al. (2008) restricts the temperature profile use to altitudes above $16 \mathrm{~km}$ and below $90 \mathrm{~km}$ (or 100 to $0.001 \mathrm{hPa}$ ).

\section{Results}

\subsection{Zonal mean of inertia-gravity wave activity}

Figure 4 shows the zonal mean of the inertia-gravity waves in July 2015 and January 2016. The standard deviations have been calculated for groups of five consecutive measurement points at the same pressure level as described in the section data analysis. Then, the standard deviations are binned with a sliding latitude window of $5^{\circ}$. Generally, the enhancement of gravity waves over the winter hemispheres has already been reported by Wu and Eckermann (2008), Ern et al. (2011), and other studies. However, Fig. 4 is calculated for inertiagravity waves. Apparently their distribution differs not so much from the distribution of high-frequency gravity waves.

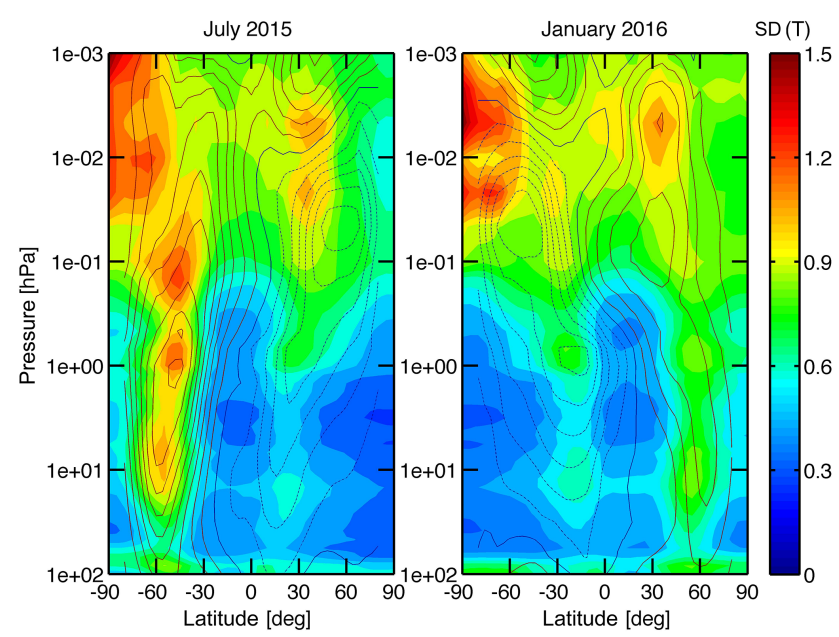

Figure 4. Monthly zonal mean of the standard deviation in temperature $(\mathrm{SD}(T))$ as retrieved from level-2 data of the satellite experiment Aura/MLS. The standard deviation is determined from five consecutive measurement points of Aura/MLS (details are given in the text). $\operatorname{SD}(T)$ can be regarded as the mean amplitude of the inertia-gravity waves. The left-hand side panel is the result for July 2015 while the right-hand side shows the result for January 2016. The contour lines show the SPARC climatology of zonal wind. Solid contour lines belong to positive eastward winds $\left(\geq 0 \mathrm{~m} \mathrm{~s}^{-1}\right)$ while dashed lines are negative eastward winds. The step size is $10 \mathrm{~m} \mathrm{~s}^{-1}$.

Contrary to other studies, Fig. 4 shows vertical modulations of $\operatorname{SD}(T)$ with scales of $10-20 \mathrm{~km}$. This modulation could be due to interactions between the inertia-gravity waves and large-scale flows such as tides, planetary waves, and vortices. The inertia-gravity waves of the southern winter stratosphere are larger than those of the northern winter stratosphere. This feature is also observed by Ern et al. (2011), who found weak gravity waves in the northern winter stratosphere compared to the southern winter stratosphere where the Andes mountain ridge and the Antarctic Peninsula are strong wavemakers. Interestingly there is enhanced gravity wave activity over northern midlatitudes in the winter mesosphere at $85 \mathrm{~km}$ altitude.

The contour lines denote the SPARC climatology of zonal wind. The monthly zonal wind climatology is derived from the UARS Reference Atmosphere Project (URAP), combining results from UK Met Office (METO) analyses with winds from the UARS High Resolution Doppler Imager (HRDI). Details of the URAP winds are described in Swinbank and Ortland (2003). Obviously, there is a relationship between waves and zonal wind in Fig. 4. The wave amplitudes are strong at the location of the polar night jets, and sometimes enhanced wave amplitudes occur in the vicinity of vertical or horizontal wind gradients. This is in agreement with the theory of spontaneous emission of inertia-gravity waves by shear flows. 
Figure 4 shows that the SPARC zonal wind climatology has enhanced eastward wind at mesospheric altitudes at northern mid-latitudes in January where also increased amplitudes of inertia-gravity waves occur. Berger (2008) performed simulations of the mesospheric wind jet and gravity waves in the winter Northern Hemisphere. They found that with increasing altitude smaller-and-smaller-scale structures develop in a zone of erosion near the border of the mesospheric jet. Further, they reported that the erosion of the mesospheric jet stream may generate new gravity wave like structures of short time periods which penetrate even higher into the lower thermosphere. We find enhanced mesospheric gravity wave activity over northern mid-latitudes not only in January 2016 but also in January 2015 so that we are quite sure that this is a regular feature.

\subsection{Global maps of inertia-gravity wave activity}

For each pressure level, the $\operatorname{SD}(T)$ values are interpolated to a regular grid with a resolution of $5 \times 5^{\circ}$ in latitude and longitude using the Delaunay triangulation method (Matlab function TriScatteredInterp.m with the option "nearest neighbor interpolation"). Figures 5 and 6 show the vertical evolution of the inertial-gravity waves in the mesosphere and the stratosphere, respectively. The colour scale of Fig. 6 is different since the $\mathrm{SD}(T)$ values are smaller in the stratosphere than in the mesosphere. First at all, we find a good agreement of the stratospheric $\mathrm{SD}(T)$ values and the patterns with the amplitudes of Aura/HIRDLS and ECMWF analysis shown in Figs. 1 and 4 of Shutts and Vosper (2011). Further, in agreement with Hendricks et al. (2014) we find a stratospheric gravity wave belt that extends eastward from the southern Andes to southeast of Australia in our Fig. 6. Going upward to mesospheric heights, the gravity wave belt changes its shape and position. At $0.01 \mathrm{hPa}$, a banana-like pattern is around the Andes in July 2015. The shape could be related to the mid-latitude tropospheric jet stream. In the stratosphere, over Scandinavia, there is enhanced gravity wave activity in the stratopause region in January 2016. This behaviour is not found for January 2015 (not shown here), but it is found in the long-term average of January data from 2002 to 2010 in TIMED/SABER data in Fig. 1 of Jia et al. (2014).

\subsection{Inertia-gravity wave activity at $100 \mathrm{hPa}$ over tropical deep convection zones}

Aura/MLS can also measure the temperature fluctuations in the tropopause region. Studies on wave activity in the upper troposphere in the tropics are rare since the separation between the atmospheric background profile and the atmospheric perturbation is ambiguous in the region around the sharp tropical tropopause. This could be a reason why Tsuda et al. (2000) selected the height region of 20-30 km (well beyond the tropical tropopause) for the retrieval of a global map of gravity wave activity from GPS radio occultation data.

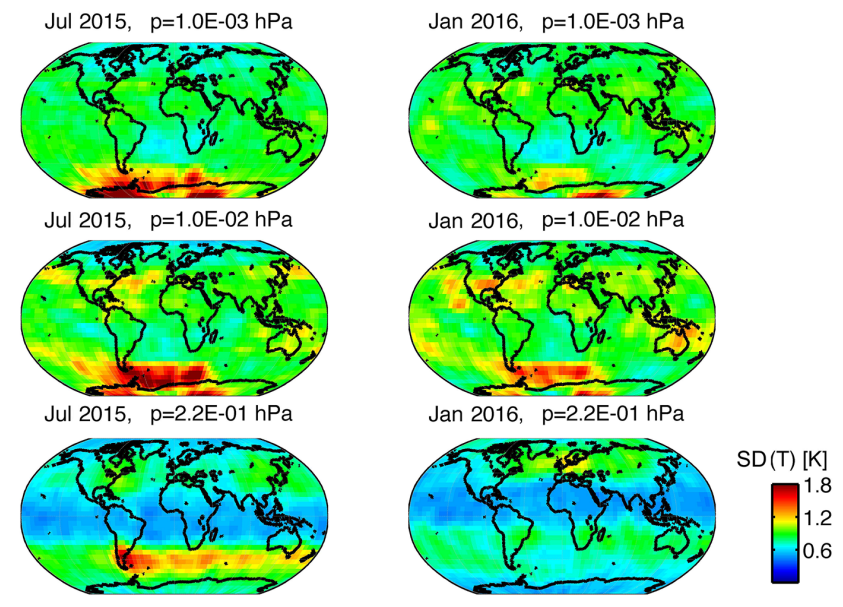

Figure 5. Global maps of inertia-gravity wave activity at various pressure levels in the mesosphere. $\operatorname{SD}(T)$ can be regarded as the mean amplitude of the inertia-gravity waves.

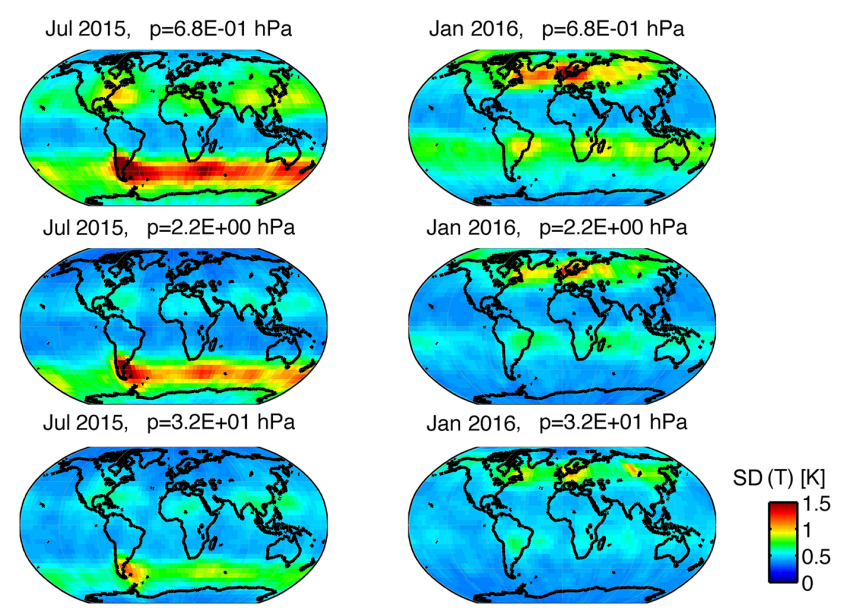

Figure 6. Global maps of inertia-gravity wave activity at various pressure levels in the stratosphere and the stratopause region. Please note that the temperature scale is different than in Fig. 5. $\mathrm{SD}(T)$ can be regarded as the mean amplitude of the inertia-gravity waves.

Further, the retrieval of high-frequency gravity wave activity from brightness temperature of AURA/MLS is restricted to the altitude region from 20 to $50 \mathrm{~km}$ where the saturation of different microwave channels occurs (Table 1 of $\mathrm{Wu}$ and Eckermann, 2008). Thus, the assessment of gravity wave activity in the tropical tropopause region was a challenge in the past. The method presented in the present paper has no problem with the derivation of inertia-gravity wave activity at $100 \mathrm{hPa}$ in the tropical tropopause region since the method evaluates the horizontal temperature variations in the vertical profiles recorded with a dense sampling along the orbit of the Aura satellite.

Figure 7a shows the result for the inertia-gravity wave activity $(\mathrm{SD}(T))$ at $100 \mathrm{hPa}(z \sim 16 \mathrm{~km})$. The global map is averaged over the time interval from December 2015 to Febru- 

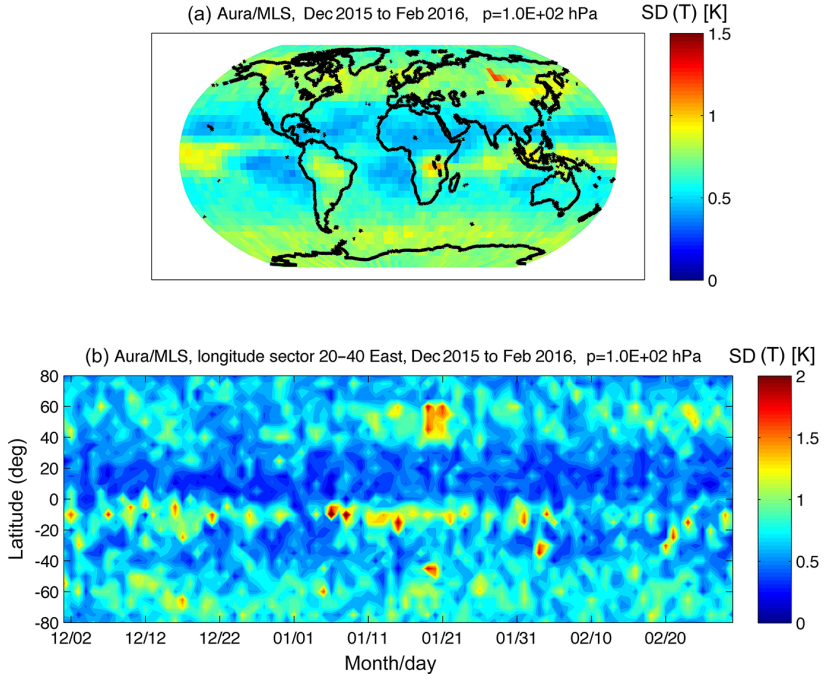

Figure 7. (a) Global map of inertia-gravity wave activity $(\mathrm{SD}(T))$ at $100 \mathrm{hPa}(z \sim 16 \mathrm{~km})$ in the upper troposphere-lower stratosphere region, averaged for the time interval from December 2015 to February 2016. (b) Temporal evolution of $\operatorname{SD}(T)$ in the African longitude sector $\left(20\right.$ to $\left.40^{\circ} \mathrm{E}\right)$.

ary 2016. The wave activity is enhanced above the tropical convection zones, namely above the Amazon region, central Africa, and Indonesia. Figure $7 \mathrm{~b}$ shows the temporal evolution of the wave activity over central Africa. $\mathrm{SD}(T)$ reaches for short time intervals amplitudes of $2 \mathrm{~K}$ and more. The $\mathrm{SD}(T)$ time series is modulated by periods of a few days to a month. For example, the wave amplitudes over central Africa are increased in mid December and mid January. It is likely that such information is valuable for validation of the inertia-gravity wave activity in atmospheric models.

\section{Conclusions}

The study showed that the dense horizontal sampling of the vertical temperature profiles from Aura/MLS allows the retrieval of the global distribution of inertia-gravity waves. Wave periods of $2-12 \mathrm{~h}$, horizontal wavelengths of 200 $1500 \mathrm{~km}$, and vertical wavelengths of $6-30 \mathrm{~km}$ efficiently contribute to the standard deviation of the horizontal temperature fluctuations. We found many patterns that were previously present in data of TIMED/SABER, Aura/HIRDLS, and ECMWF analysis. However, it seems that Aura/MLS achieves a higher vertical resolution in the gravity wave maps since the maps are derived from the analysis of horizontal fluctuations along the orbit of the sounding volume. The zonal mean of the inertia-gravity wave distribution shows vertical modulations with scales of $10-20 \mathrm{~km}$. Generally, there is a close relationship between the wave field and the zonal wind climatology. Enhanced wave amplitudes occur in regions of increased zonal wind or in the vicinity of strong wind gradients. Further, we find a banana-like shape of enhanced inertia-gravity waves above the Andes, particularly in the winter mesosphere. At northern winter midlatitudes enhanced wave activity is present at $80-90 \mathrm{~km}$ altitude (Fig. 4). Areas of enhanced inertia-gravity wave activity are found above the tropical deep convection zones at $100 \mathrm{hPa}(z \sim 16 \mathrm{~km})$. The temporal evolution of inertiagravity wave activity at $100 \mathrm{hPa}$ in the African longitude sector from December 2015 to February 2016 showed modulations of the tropical wave activity on timescales from a few days to a month. Further studies could be performed by analysing the horizontal fluctuations of other parameters such as ozone and water vapour volume mixing ratio, which are also measured by Aura/MLS. Intercomparisons of the horizontal fluctuations from Aura/MLS with coincident temporal fluctuations from ground-based remote sensing could be interesting too.

\section{Data availability}

The level-2 data are available at the Aura Validation Data Center (AVDC, 2016). The data of the viewgraphs and routines are available by the authors. The data supplement shows the gravity wave distribution for a different year.

\section{The Supplement related to this article is available online at doi:10.5194/angeo-34-781-2016-supplement.}

Acknowledgements. We thank the Aura/MLS team and NASA/JPL for the microwave limb sounding measurements and the provision of the level-2 data set at the Aura Validation Data Center (http:// avdc.gsfc.nasa.gov/). The SPARC Data Center provided the zonal wind climatology (http://www.sparc-climate.org/data-center/). We thank the reviewers and the editor for constructive suggestions and corrections.

The topical editor, C. Jacobi, thanks two anonymous referees for help in evaluating this paper.

\section{References}

Alexander, M. J., Geller, M., McLandress, C., Polavarapu, S., Preusse, P., Sassi, F., Sato, K., Eckermann, S., Ern, M., Hertzog, A., Kawatani, Y., Pulido, M., Shaw, T. A., Sigmond, M., Vincent, R., and Watanabe, S.: Recent developments in gravity-wave effects in climate models and the global distribution of gravitywave momentum flux from observations and models, Q. J. Roy. Meteor. Soc., 136, 1103-1124, 2010.

Aura Validation Data Center (AVDC): Level-2 data, available at: http://avdc.gsfc.nasa.gov/, last access: 16 September 2016.

Berger, U.: Modeling of middle atmosphere dynamics with LIMA, J. Atmos. Sol.-Terr. Phy., 70, 1170-1200, doi:10.1016/j.jastp.2008.02.004, 2008. 
Chen, C., Chu, X., McDonald, A. J., Vadas, S. L., Yu, Z., Fong, W., and Lu, X.: Inertia-gravity waves in Antarctica: A case study using simultaneous lidar and radar measurements at McMurdo/Scott Base (77.8 $8^{\circ}$ S, $166.7^{\circ}$ E), J. Geophys. Res.-Atmos., 118, 2794-2808, doi:10.1002/jgrd.50318, 2013.

Eckermann, S. D. and Preusse, P.: Global measurements of stratospheric mountain waves from space, Science, 286, 1534-1537, 1999.

Ern, M., Preusse, P., Gille, J. C., Hepplewhite, C. L., Mlynczak, M. G., Russell, J. M., and Riese, M.: Implications for atmospheric dynamics derived from global observations of gravity wave momentum flux in stratosphere and mesosphere, J. Geophys. Res.-Atmos., 116, D19107, doi:10.1029/2011JD015821, 2011.

Fritts, D. C. and Alexander, M. J.: Gravity wave dynamics and effects in the middle atmosphere, Rev. Geophys., 41, 1003, doi:10.1029/2001RG000106, 2003.

Fritts, D. C., Smith, R. B., Taylor, M. J., Doyle, J. D., Eckermann, S. D., Dörnbrack, A., Rapp, M., Williams, B. P., Pautet, P.-D., Bossert, K., Criddle, N. R., Reynolds, C. A., Reinecke, P. A., Uddstrom, M., Revell, M. J., Turner, R., Kaifler, B., Wagner, J. S., Mixa, T., Kruse, C. G., Nugent, A. D., Watson, C. D., Gisinger, S., Smith, S. M., Lieberman, R. S., Laughman, B., Moore, J. J., Brown, W. O., Haggerty, J. A., Rockwell, A., Stossmeister, G. J., Williams, S. F., Hernandez, G., Murphy, D. J., Klekociuk, A. R., Reid, I. M., and Ma, J.: The Deep Propagating Gravity Wave Experiment (DEEPWAVE): An Airborne and Ground-Based Exploration of Gravity Wave Propagation and Effects from Their Sources throughout the Lower and Middle Atmosphere, B. Am. Meteorol. Soc., 97, 425-453, doi:10.1175/BAMS-D-14-00269.1, 2016.

Grygalashvyly, M., Becker, E., and Sonnemann, G. R.: Wave mixing effects on minor chemical constituents in the MLT region: Results from a global CTM driven by highresolution dynamics, J. Geophys. Res.-Atmos., 116, D18302, doi:10.1029/2010JD015518, 2011.

Hendricks, E. A., Doyle, J. D., Eckermann, S. D., Jiang, Q., and Reinecke, P. A.: What Is the Source of the Stratospheric Gravity Wave Belt in Austral Winter?, J. Atmos. Sci., 71, 1583-1592, doi:10.1175/JAS-D-13-0332.1, 2014.

Jia, J. Y., Preusse, P., Ern, M., Chun, H.-Y., Gille, J. C., Eckermann, S. D., and Riese, M.: Sea surface temperature as a proxy for convective gravity wave excitation: a study based on global gravity wave observations in the middle atmosphere, Ann. Geophys., 32, 1373-1394, doi:10.5194/angeo-32-1373-2014, 2014.

Jiang, J., Eckermann, S., Wu, D., Hocke, K., Wang, B., Ma, J., and Zhang, Y.: Seasonal variation of gravity wave sources from satellite observation, Adv. Space Res., 35, 1925 - 1932, doi:10.1016/j.asr.2005.01.099, 2005.

Jiang, J. H., Eckermann, S. D., Wu, D. L., and Ma, J.: A search for mountain waves in MLS stratospheric limb radiances from the winter Northern Hemisphere: Data analysis and global mountain wave modeling, J. Geophys. Res.-Atmos., 109, D03107, doi:10.1029/2003JD003974, 2004a.

Jiang, J. H., Wang, B., Goya, K., Hocke, K., Eckermann, S. D., Ma, J., Wu, D. L., and Read, W. G.: Geographical distribution and interseasonal variability of tropical deep convection: UARS MLS observations and analyses, J. Geophys. Res.-Atmos., 109, D03111, doi:10.1029/2003JD003756, 2004b.
Ki, M.-O. and Chun, H.-Y.: Inertia gravity waves associated with deep convection observed during the summers of 2005 and 2007 in Korea, J. Geophys. Res.-Atmos., 116, D16122, doi:10.1029/2011JD015684, 2011.

Kumar, K. N., Ramkumar, T., and Krishnaiah, M.: J. Atmos. Sol.Terr. Phys., 73, 1890-1906, doi:10.1016/j.jastp.2011.04.026, 2011.

O’Sullivan, D. and Dunkerton, T. J.: Generation of Inertia-Gravity Waves in a Simulated Life-Cycle of Baroclinic Instability, J. Atmos. Sci., 52, 3695-3716, 1995.

Plougonven, R. and Zhang, F.: Internal gravity waves from atmospheric jets and fronts, Rev. Geophys., 52, 33-76, doi:10.1002/2012RG000419, 2014

Preusse, P., Dörnbrack, A., Eckermann, S. D., Riese, M., Schaeler, B., Bacmeister, J. T., Broutman, D., and Grossmann, K. U.: Space-based measurements of stratospheric mountain waves by CRISTA 1. Sensitivity, analysis method, and a case study, J. Geophys. Res.-Atmos., 107, 8178, doi:10.1029/2001JD000699, 2002.

Sato, K. and Yoshiki, M.: Gravity Wave Generation around the Polar Vortex in the Stratosphere Revealed by 3-Hourly Radiosonde Observations at Syowa Station, J. Atmos. Sci., 65, 3719-3735, doi:10.1175/2008JAS2539.1, 2008.

Schwartz, M. J., Lambert, A., Manney, G. L., Read, W. G., Livesey, N. J., Froidevaux, L., Ao, C. O., Bernath, P. F., Boone, C. D., Cofield, R. E., Daffer, W. H., Drouin, B. J., Fetzer, E. J., Fuller, R. A., Jarnot, R. F., Jiang, J. H., Jiang, Y. B., Knosp, B. W., Krüger, K., Li, J.-L. F., Mlynczak, M. G., Pawson, S., Russell, J. M., Santee, M. L., Snyder, W. V., Stek, P. C., Thurstans, R. P., Tompkins, A. M., Wagner, P. A., Walker, K. A., Waters, J. W., and $\mathrm{Wu}, \mathrm{D}$. L.: Validation of the Aura Microwave Limb Sounder temperature and geopotential height measurements, J. Geophys. Res.-Atmos., 113, D15S11, doi:10.1029/2007JD008783, 2008.

Shutts, G. J. and Vosper, S. B.: Stratospheric gravity waves revealed in NWP model forecasts, Q. J. Roy. Meteor. Soc., 137, 303-317, doi:10.1002/qj.763, 2011.

Suzuki, H., Nakamura, T., Vadas, S. L., Tsutsumi, M., Taguchi, M., and Fujiwara, Y.: Inertia-gravity wave in the polar mesopause region inferred from successive images of a meteor train, J. Geophys. Res.-Atmos., 118, 3047-3052, doi:10.1002/jgrd.50228, 2013.

Swinbank, R. and Ortland, D. A.: Compilation of wind data for the Upper Atmosphere Research Satellite (UARS) Reference Atmosphere Project, J. Geophys. Res.-Atmos., 108, D19, 4615, doi:10.1029/2002JD003135, 2003.

Tsuda, T., Nishida, M., Rocken, C., and Ware, R. H.: A Global Morphology of Gravity Wave Activity in the Stratosphere Revealed by the GPS Occultation Data (GPS/MET), J. Geophys. Res.Atmos., 105, 7257-7273, doi:10.1029/1999JD901005, 2000.

Vadas, S. L., Makela, J. J., Nicolls, M. J., and Milliff, R. F.: Excitation of gravity waves by ocean surface wave packets: Upward propagation and reconstruction of the thermospheric gravity wave field, J. Geophys. Res.-Space, 120, 9748-9780, doi:10.1002/2015JA021430, 2015.

Waters, J. W., Froidevaux, L., Harwood, R. S., Jarnot, R. F., Pickett, H. M., Read, W. G., Siegel, P. H., Cofield, R. E., Filipiak, M. J., Flower, D. A., Holden, J. R., Lau, G. K. K., Livesey, N. J., Manney, G. L., Pumphrey, H. C., Santee, M. L., Wu, D. L., Cuddy, D. T., Lay, R. R., Loo, M. S., Perun, V. S., Schwartz, M. J., Stek, 
P. C., Thurstans, R. P., Boyles, M. A., Chandra, K. M., Chavez, M. C., Chen, G. S., Chudasama, B. V., Dodge, R., Fuller, R. A., Girard, M. A., Jiang, J. H., Jiang, Y. B., Knosp, B. W., LaBelle, R. C., Lam, J. C., Lee, K. A., Miller, D., Oswald, J. E., Patel, N. C., Pukala, D. M., Quintero, O., Scaff, D. M., Van Snyder, W., Tope, M. C., Wagner, P. A., and Walch, M. J.: The Earth Observing System Microwave Limb Sounder (EOS MLS) on the Aura satellite, IEEE T. Geosci. Remote, 44, 1075-1092, 2006.
Williams, P. D., Read, P. L., and Haine, T. W. N.: Spontaneous generation and impact of inertia-gravity waves in a stratified, two-layer shear flow, Geophys. Res. Lett., 30, 2255, doi:10.1029/2003GL018498, 2003.

Wu, D. L. and Eckermann, S. D.: Global Gravity Wave Variances from Aura MLS: Characteristics and Interpretation, J. Atmos. Sci., 65, 3695-3718, doi:10.1175/2008JAS2489.1, 2008. 